\title{
圈 the COVID-19 Pandemic \\ A Study of the Socio-Economic Implications of
}

\author{
Shouvik Lahiri ${ }^{1}$ and Manish Sinha ${ }^{2}$
}

\begin{abstract}
Purpose: The COVID-19 pandemic has raised concerns of an imminent economic crisis, feared to be much worse than the Great Depression. Although the pandemic is global, its impact is deeply local. This paper aims to determine the socio-economic implications of the COVID-19 pandemic, particularly on the various organisations and on the consumption patterns of individuals. On the social front, there will be a look into how social distancing, panic buying and other preventive measures necessitated by this pandemic have altered the behavioural pattern of individuals in their interactions with other economic agents.
\end{abstract}

Design/Methodology/Approach: The methodology adopted is a qualitative one, where in-depth interviews were conducted across various sectors. Our focus is primarily on changes in consumption and occupational patterns. Accordingly, interviews of household members, labourers and employers have been conducted. Such a study will have practical implications in terms of helping to build theory and policy.

Findings: This study has analysed how global pandemics alter individual behaviour, from a socioeconomic standpoint.

Practical/Theoretical Implications: This research will prove useful in predicting human behaviour during any 'flu-like' epidemic in the future.

JEL classification: M12, M14, J31

Keywords: COVID-19, pandemic, behavioural, consumption, socio-economic

\footnotetext{
${ }^{1}$ Symbiosis Centre for Management \& Human Resource Development, Symbiosis International (Deemed University), Pune, India.

Email address: shouvik_lahiri@scmhrd.edu

${ }^{2}$ Symbiosis Centre for Management \& Human Resource Development, Symbiosis International (Deemed University), Pune, India.

Email address : manish_sinha@scmhrd.edu
} 


\section{INTRODUCTION}

An infinitesimally small, yet infinitely lethal entity, the coronavirus, referred to hereinafter as COVID-19, caused the world to come to a standstill in the early months of 2020. The extremely sudden and exponentially accelerated spread of this virus has left the entire world in shock, with nearly no country able to manage the outbreak and keep it under control. The very first cases of COVID-19 were reported in Wuhan, China in December 2019. Since then, it has spread to over 227 countries, infecting over 10.7 million people and causing over 5,00,000 deaths, as of 4 July 2020 (WHO Coronavirus Disease (COVID-19) Dashboard, 2020). In comparison to previous global pandemics such as Severe Acute Respiratory Syndrome (SARS) and Middle East Respiratory Syndrome (MERS), COVID-19 has resulted in much higher number of infections and deaths. It was declared a global pandemic by the World Health Organization (WHO) on 11 March 2020, and is still ongoing till date.

India currently ranks 4th among all the countries in the world in terms of the number of confirmed cases. As on 4 July 2020, there have been 625,544 cases throughout the country, with 18,213 deaths (WHO Coronavirus Disease (COVID-19) Dashboard, 2020). The first confirmed case of COVID-19 in India was reported on 30 January 2020 in Kerala, in a student who was visiting home on a vacation from Wuhan University in China.

Figure 1: The date-wise number of cases, deaths and recoveries in India in the last 21 days

\begin{tabular}{|c|c|c|c|c|c|c|}
\hline \multicolumn{7}{|c|}{$\begin{array}{l}\text { COVID-19 cases in India }(\mathrm{v} \cdot \mathrm{T} \cdot \mathrm{E}) \\
\text { Deaths Recoveries Active cases }\end{array}$} \\
\hline & Jan 30 & Feb 2-21 & Mar 2-31 & Apr $1-30$ & May 1-31 Jun 1-12 & Last 21 days \\
\hline Date & & & & & \# of cases & \# of deaths \\
\hline $2020-06-13$ & & & & & $308,993(+3.9 \%)$ & $8,884(+4.5 \%)$ \\
\hline $2020-06-14$ & & & & & $320,922(+3.9 \%)$ & $9,195(+3.5 \%)$ \\
\hline $2020-06-15$ & & & & & $332,424(+3.6 \%)$ & $9,520(+3.5 \%)$ \\
\hline $2020-06-16$ & & & & & $343,091(+3.2 \%)$ & $9,900(+4 \%)$ \\
\hline $2020-06-17$ & & & & & $354,065(+3.2 \%)$ & $11,903(+20 \%[)$ \\
\hline $2020-06-18$ & & & & & $366,946(+3.6 \%)$ & $12,237(+2.8 \%)$ \\
\hline $2020-06-19$ & & & & & $380,532(+3.7 \%)$ & $12,573(+2.7 \%)$ \\
\hline $2020-06-20$ & & & & & $395,048(+3.8 \%)$ & $12,948(+3 \%)$ \\
\hline $2020-06-21$ & & & & & $410,461(+3.9 \%)$ & $13,254(+2.4 \%)$ \\
\hline $2020-06-22$ & & & & & $425,282(+3.6 \%)$ & $13,699(+3.4 \%)$ \\
\hline $2020-06-23$ & & & & & $440,215(+3.5 \%)$ & $14,011(+2.3 \%)$ \\
\hline $2020-06-24$ & & & & & $456,183(+3.6 \%)$ & $14,476(+3.3 \%)$ \\
\hline $2020-06-25$ & & & & & $473,105(+3.7 \%)$ & $14,894(+2.9 \%)$ \\
\hline $2020-06-26$ & & & & & $490,401(+3.7 \%)$ & $15,301(+2.7 \%)$ \\
\hline $2020-06-27$ & & & & & $508,953(+3.8 \%)$ & $15,685(+2.5 \%)$ \\
\hline $2020-06-28$ & & & & & $528,859(+3.9 \%)$ & $16,095(+2.6 \%)$ \\
\hline $2020-06-29$ & & & & & $548,318(+3.7 \%)$ & $16,475(+2.4 \%)$ \\
\hline $2020-06-30$ & & & & & $566,840(+3.4 \%)$ & $16,893(+2.5 \%)$ \\
\hline 2020-07-01 & & & & & $585,493(+3.3 \%)$ & $17,400(+3 \%)$ \\
\hline $2020-07-02$ & & & & & $604,641(+3.3 \%)$ & $17,834(+2.5 \%)$ \\
\hline $2020-07-03$ & & & & & $625,544(+3.5 \%)$ & $18,213(+2.1 \%)$ \\
\hline
\end{tabular}

Source: https://www.mohfw.gov.in/ 
To combat this pandemic, the Indian government had announced several phases of lockdown, spanning over two months. There were also a series of social distancing measures and travel restrictions to aid in flattening the curve. Right now, the 'unlock' phase is going on, whereby the government is looking to gradually phase out the restrictions, and show more leniency on curfews and transportation.

It will be an understatement to say that this pandemic has affected the lives of a large section of the Indian population. Daily wage earners, migrant workers and factory-level employees face uncertainty and hardships due to halt in businesses. The unorganised sector is facing unprecedented losses amid strict lockdown restrictions over the past two months. Several employees have lost their jobs, while many others have had to accept pay cuts and curtailment of benefits. Businesses are finding it hard to bounce back from the position of no or very little sales in the past two months, while students and recent graduates are looking at a potentially bleak job market and future prospects. Meanwhile, the average Indian household is having to rethink its spending plans and readjust its lifestyle pattern in light of fear, anxiety and uncertainty. Indeed, the implications of a VUCA (Volatility, Uncertainty, Complexity and Ambiguity) world have never been more profound.

In light of all this, a deep dive into the socio-economic implications of the pandemic might throw up a lot of useful insights with regard to changes in human behaviour and lifestyle. Some of these changes might become permanent, as we accustom ourselves to the new normal. India, particularly, has not yet been able to bend the curve, in terms of rise in number of cases, post implementation of lockdown. This has led to serious concerns, but in a country with such a huge population, it takes a herculean effort on behalf of all citizens to curb the flow. This is why, more than ever, the behaviour of individuals, families, businesses and the society in general needs to be predicted, and better policies framed, in the unfortunate event of a future pandemic. This will help to reduce the suffering and drastically minimize the death toll, as well as give the citizens encouragement to stay safe at home without worrying too much about their lives, livelihood and well-being.

A research into the socio-economic impact of COVID-19 and lockdown can be done to address specific problems faced by different classes of society. The socio-economic indicators can be education, employment and income levels. Along these three categories, specific research questions that are to be discussed include how the pandemic has affected people's health, with regard to their type of job; how mental health of students is being affected at different levels of education; and how the households are getting impacted in terms of their buying patterns, savings and lifestyle changes on account of the lockdown.

\section{LITERATURE REVIEW}

Throughout history, pandemics have had three broad kinds of economic impact - direct costs, long-term burden and indirect costs. Direct costs can be really high - for example, during the Ebola outbreak, it amounted to 3 years of funding for WHO. One of the main long-term burdens is loss of earnings of those who died, estimated to be around 80 per cent of the global economic losses. Indirect costs include anything that contributes to a decline in GDP. SARS outbreak of 2003 caused the annual GDP of China to decrease by 1 per cent and that of South-East Asia by 0.5 per cent (Qui, Rutherford, Mao \& Chu, 2017). During the SARS outbreak of 2003, estimates and models 
predicted a catastrophic impact on the global macroeconomic scenario. However, it was later found that the actual impact was far less. The South-East Asian economies, where the outbreak was the most severe, were the worst affected, and sectors such as investment, retail sales, restaurants, hotels, tourism and air transport took a huge hit too. There appears to be a positive correlation between severity of outbreak and severity of impact (Keogh-Brown \& Smith, 2008). The Iraq war, threat of terrorism and SARS have all had a combined effect on international business and hence led to an economic crisis in South-East Asia. This has paralyzed just-in-time supply chains and caused a crisis for retailers and other businesses worldwide. However, there were certain unintended benefits too, such as video conferencing helping to cut costs at all companies or new businesses for private jet carriers and more business to Las Vegas, which had become something of a safe haven, due to zero SARS cases (Overby, Rayburn, Hammond \& Wyld, 2004).

Economic Implications: The ongoing COVID-19 outbreak is going to affect developing Asian economies in various ways, such as decline in domestic demand, tourism, trade and production, supply disruptions and health effects. Since the magnitude of this impact depends on how long the pandemic lasts, different scenarios need to be explored to assess the probable impact. The range of scenarios explored suggests a possible impact of 0.1 per cent to 0.4 per cent of global GDP. Two-third of this impact is likely to fall upon China (Abiad et al., 2020). India is going to be one of the top 15 countries to be worst affected by COVID-19, with an estimated economic impact of 348 million dollars. The trade impact is predicted to be most for the chemicals sector, textiles and apparel, automotive and electrical machinery, among others. This is because around one-third of the machinery and two-fifths of organic chemicals imports comes from China (Kumar, Thombare $\&$ Kale, 2020). COVID-19 has managed to stifle economic activities in two ways - first, social distancing was necessitated, which led to shutdown of financial markets, corporate offices, businesses and events. Second, the exponential rise in the spread of the virus, and the uncertainty surrounding it, led to a frenzied flight to safety in consumption and investment among consumers, investors and businesses. This outbreak has triggered a global recession in 2020, which was a reflection of the difficult choice that many countries had to make in order to save their people rather than their economies. Some countries, however, have used this as an opportunity to revamp their economic and financial systems with planned federal stimulus packages (Ozili \& Arun, 2020).

Socio-Economic Impact: Given the positive correlation between population density and mortality rate during the 1918 pandemic, we may expect more deaths in urban areas. However, since the world is more connected now, the difference between rural and urban deaths may come down. In the US, urban dwellers are likely to have more access to quality healthcare, but question remains of the affordability of the said healthcare, especially among the middle income class. Moreover, healthcare includes having a system in place to rapidly dispose of the dead and provide safety equipment to healthcare workers. If the pandemic causes shortage of employees, there can be a wage hike for existing employees, though this is less likely than in 1918, given the greater mobility of workers today (Garrett, 2007). Historically, pandemic mortality has been the highest among those with the lowest socio-economic status. This group must be prioritized for pandemic vaccination, and thus need to be included in the preparedness plans for pandemic influenza. A reduction in social inequality will also reduce the socio-economic risk factor in the spread of future pandemics (Mamelund, Shelley-Egan \& Rogeberg, 2019). 
Impact on Income: While discussing the links between income and infectious disease epidemics, it was found that the richer a person is, the more immune he/she is to a health setback, even during an epidemic. Better health leads to more productivity and investment and boosts economic growth of a country. Including the value of human life in the costs associated with an epidemic makes it very costly indeed, and long-term vulnerability to epidemics shall rise further in a more interconnected world (Bloom \& Canning, 2004). The impoverished are facing enormous challenges due to this pandemic, as it is nearly impossible for them to survive while adhering to the social restrictions amid lockdown. The main concern in developed nations is the long-term impact, potentially leaving millions of people unemployed. Separate special lockdown and national emergency rules for the poorer sections of society is a recommendation for any similar future scenario in the developing countries (Buheji, Mavric \& Cunha, 2020).

Impact on Education: COVID-19 poses serious concerns to the global education system. A study has indicated that there have been severe learning disruptions, and reduced access to education infrastructure and research facilities in recent times. Students are feeling the burden of education loans more than ever now, and also are dealing with problems such as poor connectivity, electricity and technological issues (Onyema et al., 2020).

Impact on Employment: Meanwhile, the link between outbreaks and productive labour supply is studied, with reference to morbidity, mortality and additional absenteeism, to indicate that the economic cost of communicable diseases, particularly outbreaks of infectious diseases, is more than the amount of their direct health effects. Interactions between various sectors of the economy and the processes of combining output factors with externalities associated with transmissible diseases suggest that a macroeconomic analysis, however important, is unlikely to factor in the 'societal' cost, which is too high (Keogh-Brown, 2014). There has been a significant reduction in demand and supply in various sectors due to travel restrictions and lockdown measures. Supply chain has been disrupted, halting manufacturing, and prices of commodities such as oil are on a free fall. There have also been massive job losses, particularly among the migrant labour force. All of this threatens to reverse all the progress made in the fight against poverty in the developing nations (United Nations Report, 2020).

Behavioural economics studies have suggested that governments often use strategies to conceal information from the public to reduce unwarranted panic during such pandemics. Honesty may not be the best policy, since a premature announcement may lead to severe economic losses because of mass hysteria, excessive preventive actions and trade restrictions by foreign governments (Brahmbhatt \& Dutta, 2008). A large scale survey of the Spanish citizens' perception about COVID-19 in four areas, namely, their social contact behaviour during confinement, personal economic impact, workplace situation and health status revealed that the level of resilience and compliance with all the strict measures was very good in the Spanish population. Smaller companies were hit the hardest economically, while socio-economic impacts between different gender and age categories was widely varied (Oliver, Barber, Roomp \& Roomp). Another survey, of the knowledge, attitude and practices of Chinese citizens of high socio-economic status revealed a significant negative correlation between COVID-19 knowledge and negative attitudes towards preventive measures. However, women in particular have a much more positive attitude and this attitude comes from health education programmes during times of crisis (Zhong et al., 2020). 


\section{RESEARCH METHODOLOGY}

Three separate questionnaires, one for each of the socio-economic agents described above, were created, having open-ended questions. The questions mainly focused on the three major areas of concern for students, households and employees/businessmen. The questionnaire for employees/businessmen had 25 questions, while that for students had 17 and the one for households had 16 questions. Convenience non-probability method of sampling was used to target the respondents who were easily available and who fit into one of the three categories. In-depth interviews of such respondents were taken to gauge the impact this pandemic, coupled with the lockdown has had on them.

The questionnaires were created via 'questionpro', and initially around 20 responses for each category were targeted. The first section of all three categories had the common questions of age, gender, average family income, state of residence and number of family members. Under the 'Households' category, questions such as economic impact of the lockdown on the family spending, difference in savings and investment patterns, change in mentality while going out, usage of transport, reasons for leaving home during the lockdown and comments on the effectiveness of government measures were solicited. For the 'Students', questions mainly revolved around their perceptions about online classes, online examinations and the various challenges they have had to face for this shift from physical classrooms. The 'Employees/Businessmen' were asked about the impact on their respective organisations, what it meant for them in terms of job losses or pay cuts, and the intricacies of 'work from home' becoming the new normal.

In the end, 25 responses from 'Employees/Businessmen', 19 from 'Students' and 22 from 'Households' were received. All respondents were from India, although the states varied somewhat.

\section{RESULTS AND ANALYSIS}

(a) Socio-Economic Impact of COVID-19 on Indian Households

Out of the total 22 respondents, 12 were females and 10 males. Most respondents were from the states of West Bengal and Maharashtra, and some from Madhya Pradesh, Odisha, Assam and Uttarakhand as well. The average age of respondents was around 37 years, and family income estimated at Rs. 11.2 lakhs per annum. Their demographics distribution (gender and age) as well as number of family members are given below:

Figure 2: Age distribution for 'Household' respondents

\begin{tabular}{|c|c|c|c|c|c|}
\hline & & Frequency & Per cent & $\begin{array}{ll}\text { Valid } & \text { Per } \\
\text { cent }\end{array}$ & $\begin{array}{l}\text { Cumulative } \\
\text { Per cent }\end{array}$ \\
\hline Valid & 23 & 1 & 4.5 & 4.5 & 4.5 \\
\hline & 24 & 7 & 31.8 & 31.8 & 36.4 \\
\hline & 25 & 3 & 13.6 & 13.6 & 50.0 \\
\hline & 27 & 1 & 4.5 & 4.5 & 54.5 \\
\hline & 32 & 1 & 4.5 & 4.5 & 59.1 \\
\hline & 47 & 1 & 4.5 & 4.5 & 63.6 \\
\hline
\end{tabular}


Lahiri \& Sinha $\mid$ A Study of the Socio-Economic Implications of the COVID-19 Pandemic

\begin{tabular}{|l|l|l|l|l|}
\hline 52 & 1 & 4.5 & 4.5 & 68.2 \\
\hline 54 & 1 & 4.5 & 4.5 & 72.7 \\
\hline 56 & 2 & 9.1 & 9.1 & 81.8 \\
\hline 57 & 2 & 9.1 & 9.1 & 90.9 \\
\hline 59 & 1 & 4.5 & 4.5 & 95.5 \\
\hline 62 & 1 & 4.5 & 4.5 & 100.0 \\
\hline Total & 22 & 100.0 & 100.0 & \\
\hline
\end{tabular}

Figure 3: No. of family members for 'Household' respondents

\begin{tabular}{|lll|l|l|l|}
\hline & Frequency & Per cent & & $\begin{array}{l}\text { Cumulative } \\
\text { Per cent }\end{array}$ \\
\hline \multirow{3}{*}{ Valid } & 3 & 8 & 36.4 & 36.4 & 36.4 \\
\cline { 2 - 6 } & 4 & 11 & 50.0 & 50.0 & 86.4 \\
\cline { 2 - 5 } & 5 & 3 & 13.6 & 13.6 & 100.0 \\
\cline { 2 - 5 } & Total & 22 & 100.0 & 100.0 & \\
\hline
\end{tabular}

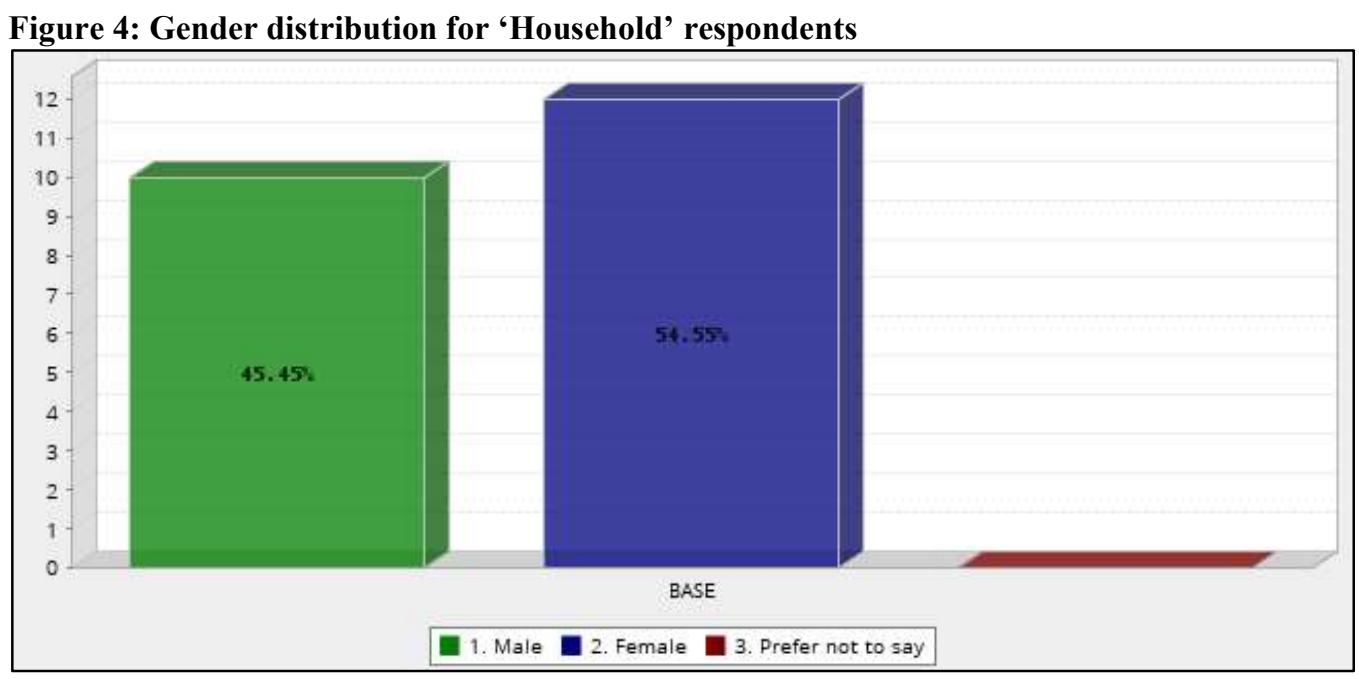

When asked for what purpose they had to leave their house in the last two months, most of the respondents $(86.36 \%)$ answered it was for buying groceries, so we may conclude that most did not venture out unless absolutely necessary. While visiting any place these days, the major concern people have seems to be that of social distancing $(40.9 \%$ of them highlighted that as the first issue), followed by proper use of PPEs by everyone around them $(22.72 \%)$ and hygiene and fear of contracting the virus $(18.18 \%)$ each. The economic impact of the lockdown is mainly felt in terms of impact on livelihood of the respondents (27.27\% of them feared that), as well as lifestyle changes they have been forced to make $(22.7 \%$, most of whom fell in the below Rs. 10 lakhs annual income bracket). A meagre 18 per cent of the respondents thought that the central government is doing a good job to stop the spread of the virus, while the rest did not agree. 
(b) Socio-Economic Impact of COVID-19 on Students

The student respondents for this survey were chosen mainly out of graduates pursuing their master's degree. So, the age range is between 20 and 25 years. The demographics are illustrated below:

Figure 5: Gender distribution for 'Student' respondents

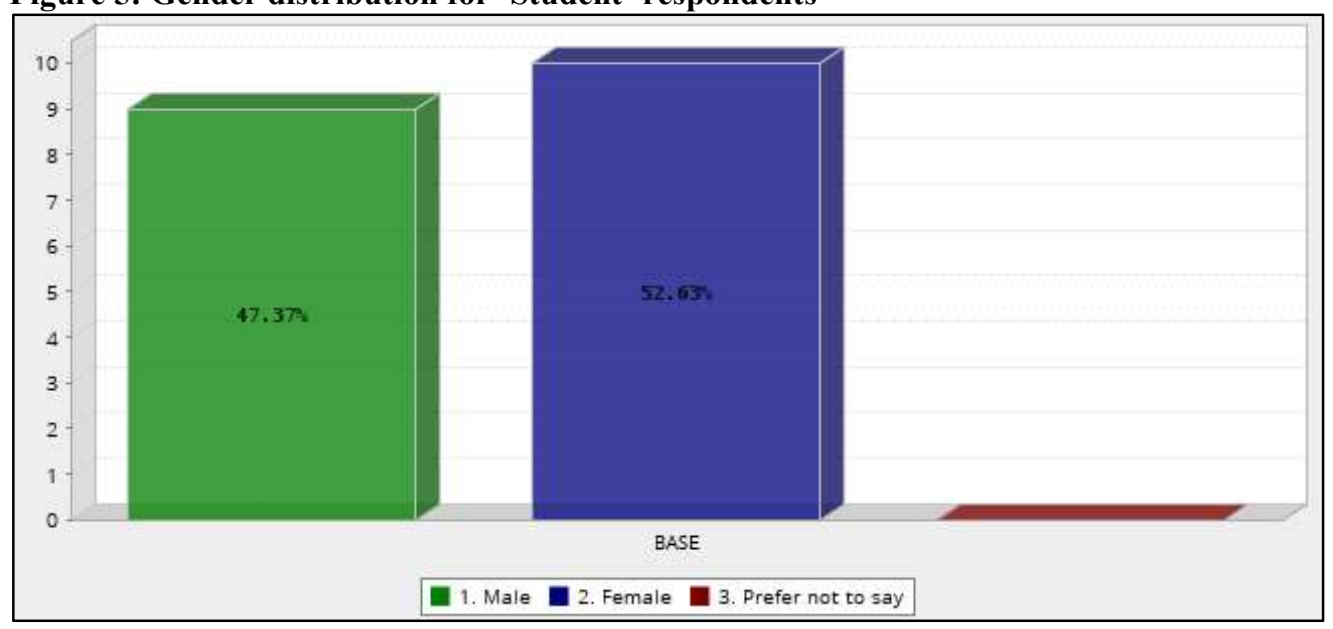

Figure 6: Level of education for 'Student' respondents

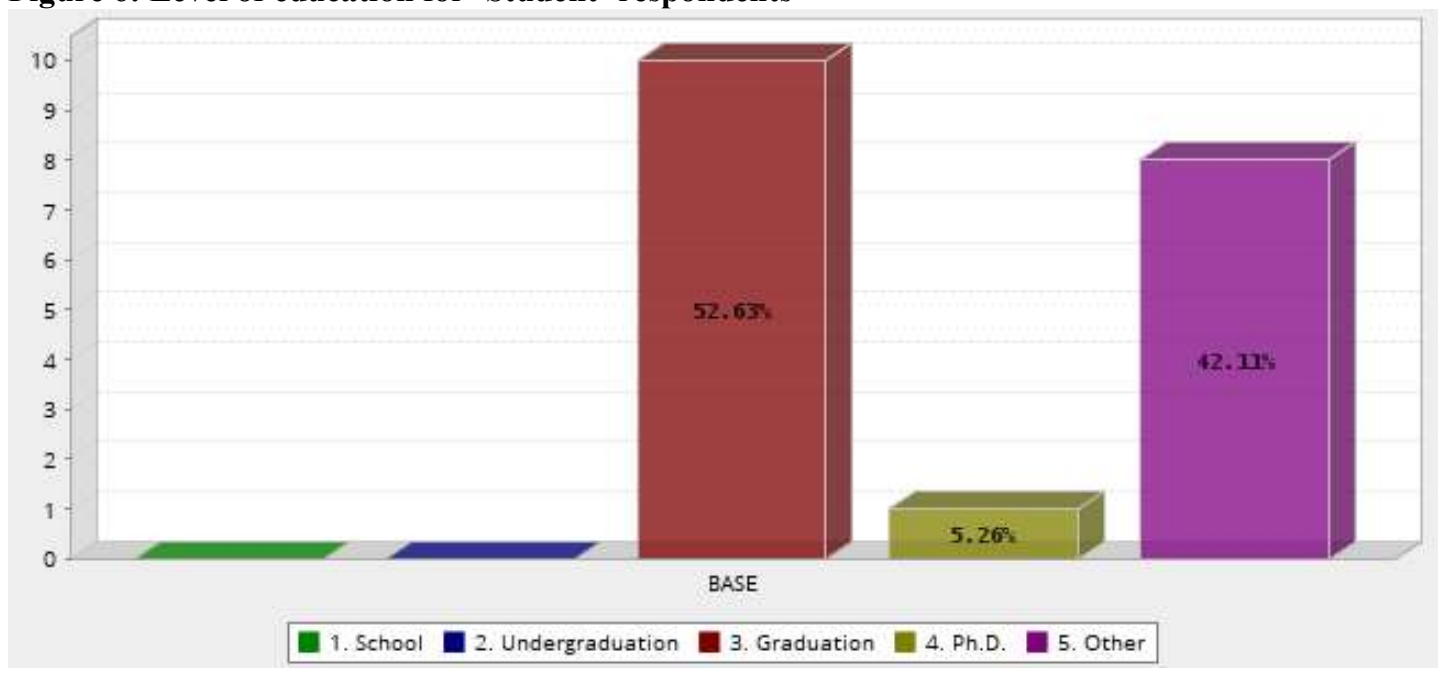

The above chart indicates that most of the respondents are currently pursuing a master's degree. The category 'Other' indicates those who are not currently enrolled in any formal institute, but are either preparing for an entrance examination or seeking jobs. When asked the question about the current status of classes, most respondents said that online classes will begin soon, and some of them have those classes going on right now. The distribution is as below: 
Lahiri \& Sinha $\mid$ A Study of the Socio-Economic Implications of the COVID-19 Pandemic

Figure 7: Status of classes for 'Student' respondents

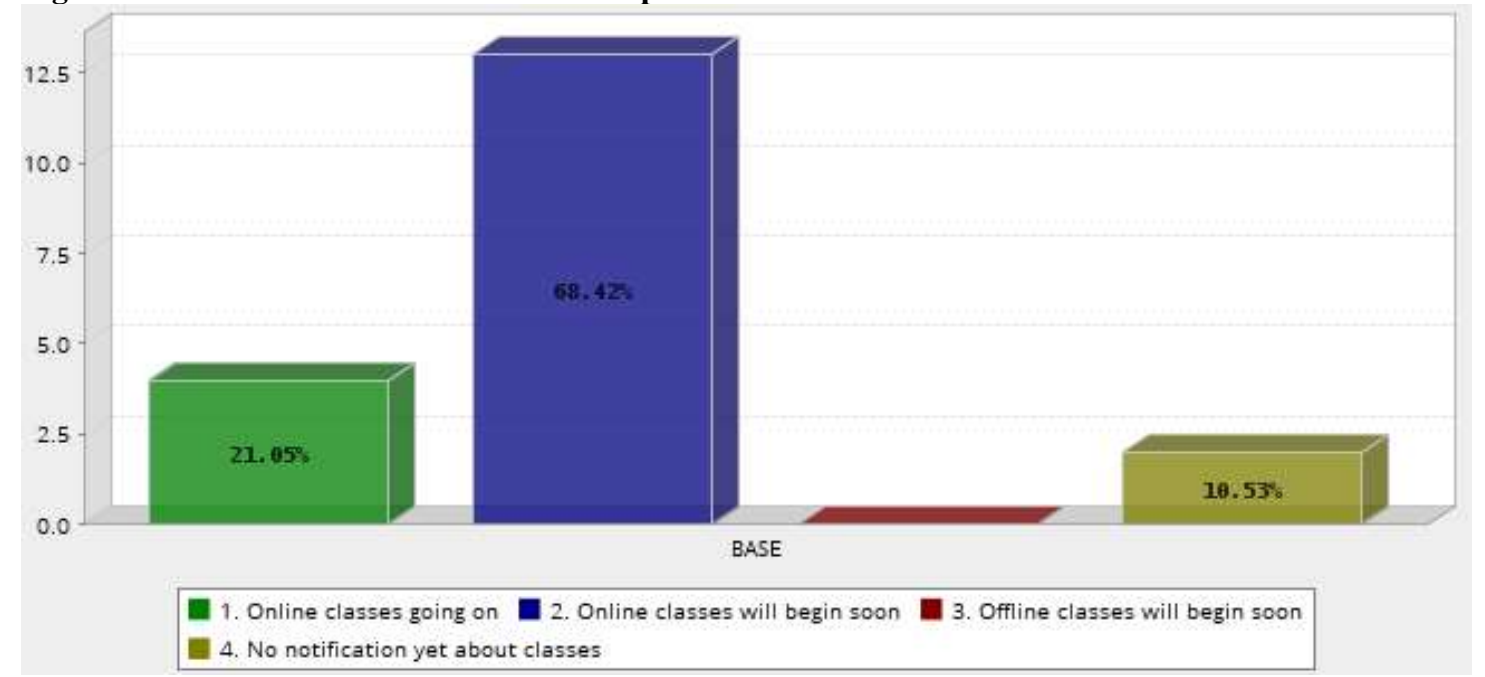

Of all the respondents, 59.09 per cent remarked that the absence of a physical classroom was the most acute problem, while 41 per cent believed that internet connectivity issues posed a major threat to online classes. The ways in which this has affected the students include challenges of technology in having to shift to this virtual mode (32\% responses each) and also time management and motivation issues (16\% each). This appears to be gender-agnostic, as there is no significant difference in the problems stated by both genders. Taking examinations online too seemed to be a nuisance to most, without gender or level of education being a factor. The major area of concern, for over 90 per cent of the respondents, has been internet connectivity, and also apprehension about the mode of the online examination.

(c) Socio-Economic Impact of COVID-19 on Employees/Businessmen

We interviewed 24 working professionals and 1 business owner, once again concentrated mainly in the states of Maharashtra and West Bengal. Their age ranged from early 20 s to mid-50s, and their respective organisations belonged to a wide spectrum of industries. The mean income among the respondents was Rs. 12 lakhs per annum, and they were mostly in some level of management. 
Figure 8: Gender distribution for 'Employee' respondents

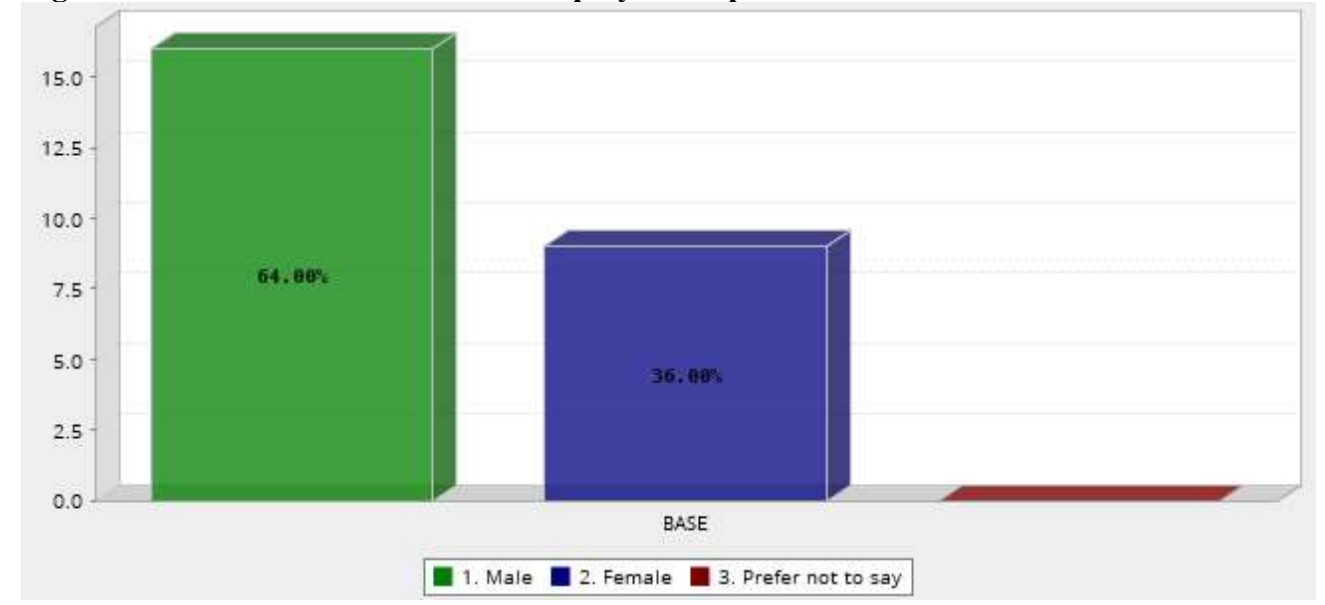

While the sectors varied a lot, and were unique for most respondents, such as shipping, manufacturing, financial services, e-commerce, banking, media and entertainment, information technology services clearly was the most common profession, with 36 per cent of them working in IT. Almost 88 per cent of the respondents had not gone to work even for a single day in the last two months, though 84 per cent of them had to work from home. For the rest, it has been an anxious wait for their offices to reopen. Around 12 per cent believed that their organisation runs the risk of being shut down due to this pandemic. Exactly 28 per cent faced some form of job-related setbacks during this lockdown, such as pay cuts, curtailment of benefits or salary hike freeze.

\section{DISCUSSION}

(a) Impact on Households

The severity of socio-economic impact of this pandemic can be well understood by studying the changes in buying behaviour and social interactions of the citizens post lockdown. While lockdown may be lifted partially, it is important to remember that the virus still exists. So, while venturing out of their homes, the respondents had several concerns. These could be labelled under five categories - 'fear of COVID-19 and social distancing concerns', 'hygiene and PPE', 'shifts in lifestyle', 'perception about government's role' and 'economic impact on households'.

(i) Fear of COVID-19 \& Social Distancing Concerns: Before this pandemic, we never used to be bothered by coming in contact with persons. In fact, most of our daily transactions involved exchange of money by hand. However, currently, people have become extremely cautious about what they are touching and who they are coming in direct contact with. Social distancing is actually something that might save someone's life at this point. Some respondents expressed their hesitation to visit places or shops that were crowded, while some others feared that this entire concept of social distancing might not be possible to implement while travelling and attending social events. The fear of contracting the virus 
by coming in contact with an infected person appears to be very high among this pool of respondents. That is why even after lockdown, footfall in shops and stores is likely to be less. This fear can only be overcome if the person is assured that the place is properly sanitized and very hygienic.

(ii) Hygiene \& PPEs: Good customer service will henceforth require these basic tweaks, alongside the attendant wearing a mask at all times. So, using proper PPEs and following all COVID related protocols stringently can make a huge difference in the footfall, and consequently sales, of shops and establishments post lockdown. The fear that has overridden the minds will gradually dissipate, but following these protocols will be the new normal.

(iii) Shifts in Lifestyle: While three of the respondents confessed that they had not left their house at all in the past two months, most others said they left home only when absolutely necessary. Those employed in essential services had no choice but to report for duty every day, thus being exposed to higher risk of contracting the virus than those who stayed at home. Some respondents said they had to leave their home for health-related matters, such as a doctor's appointment or regular check-ups. This does spring a surprise, as some respondents who were doctors did point out that their patients have been hesitant to come for regular appointments. So, it seems to be more of an issue about age, as the more elderly respondents said they made sure they kept their appointments, amid all the risk, while the younger ones decided to postpone such visits.

Most respondents said they preferred to go to the nearest available grocery store, and could not yet rely totally on online grocery delivery platforms. The main issue is of freshness, as even with the risk of infection, people would prefer ensure that they got the most fresh and best quality fruits, vegetables and fish. The marketplace can turn into a hotspot really quick, if even one person who visits or sets up shop over there is infected. That is why we saw so many markets getting sealed off in most major cities, resulting in shortage in supply of fruits and vegetables, and people having to go farther and farther away from their homes in search of these items. There have been some who just went to visit their friends and relatives during this lockdown, while some visited their bank and some others only went for walks. It was essential to note that all of the respondents affirmed that they wore a mask at all times and kept small bottles of sanitizers with them.

(iv) Perception about Government's Role: While there are some who believe that the central government has done enough, or as much as they could have done to curtail the spread of the virus in India, most respondents were of the opinion that the measures undertaken by the government have been grossly inadequate. The findings are consistent with those that criticized the role of the government during pandemics (Brahmbhatt \& Dutta, 2008). Some have been of the opinion that their local governments are doing a much better job, and what has worked for the local government has been mainly having a proactive attitude for timely response. The popular sentiment on this issue has been that the central government has delayed a lot in taking action, be it in implementing the lockdown or tendering more PPEs and testing kits. The responses to this particular question can be classified under six broad categories - 'early response', 'citizens' role', 'tighter 
rules', 'lockdown policy', 'increased testing' and 'more PPEs'. Under the first category, a couple of respondents felt that the government simply did not respond quickly enough, else the spread of the virus could have been restricted. This is consistent with the graph shown above. Those who advocated that the government did the best it could (a mere $18 \%$ of the respondents thought so) were of the opinion that it is now the citizens' role to act more responsibly and curb the spread by following the safety and social distancing norms. There is a need for citizens to stay at home as much as possible, venturing out only when absolutely necessary. This poses a real challenge, especially now, since most companies, malls, shops and public places are opening up gradually. Some of the respondents who said that the government was not doing enough were, however, quick to praise their respective local governments and their efforts. Mostly the local governments were successful in implementing tighter rules all over the state, thus preventing cases from rising. Case in point would be the Uttarakhand government, as one of the respondents from Bhimtal, a small town in Uttarakhand, was effusive in his praises of the strict restrictions put in place. These restrictions include institutional quarantine for people coming from states with high number of cases, a 14-day home quarantine for the rest and fines for not wearing masks in public. The most common point in this argument has been to regularly inspect whether shops and other establishments are maintaining the protocols put in place, and the need for more police force to ensure all lockdown regulations are followed to the letter. With regard to the lockdown policy, respondents felt that it should be made with further restrictions, and should not be limited to containment zones even now. The respondents especially from Maharashtra, a state where the number of cases kept rising exponentially, insisted that lockdown needed to be extended further, with some going to the extent of suggesting that it should be a total shutdown, with no one allowed to venture out. Those in favour of more testing said that testing needs to be scaled up, and there should be enhanced testing by spreading awareness and letting people know what symptoms to watch out for, and at what stage they should approach doctors. The need for PPEs and safety kits is acute as well, considering that these are essential not only for the common public, but also the healthcare workers and doctors, who cannot treat the COVID-19 patients without such equipment. Consequently, masks and sanitizers have become essentials now, and they should be made easily available, according to some respondents.

(v) Economic Impact on Households: One of the biggest questions going around has been, how has the virus, along with this extensive lockdown period, affected the people economically? It is no mystery that several companies around the world have been affected by this pandemic in a negative way. Similarly, individuals around the world have been affected too, on account of job losses, pay cuts and other issues. So many of the respondents harped on the theme 'impact on livelihood' while answering this question, while others, mainly professionals and businessmen, talked about 'reduced customers/clients' and 'lifestyle changes'. The world has had to make a tectonic shift to working from home via online technology, so the theme of 'change to online' came up too. And finally, a few of the respondents said that they or their family members enjoyed 'security of work', so were not affected too much by this pandemic. This is in line with the literature that the richer a person is, the more immune his family is to such a crisis (Bloom \& Canning, 2004). 
The impact on livelihood was felt mostly by those whose earnings depended on daily running of operations, such as doctors, hotel owners and garment merchants. This is intertwined with loss of customers/clients - people are hesitant in this lockdown to go out and would rather postpone their needs. As per the dynamics of demand and supply, postponement of consumption leads to a decrease in demand at present, thus bringing down the prices of such goods or services. This is digging quite a deep hole and bringing about apprehension and anxiety in the minds of such families. Furthermore, the same people said that they had to cut down on their own consumption expenditure drastically, as they are dependent mainly on their savings. Spending on any kind of luxury item seems like a thing of the past for now. There has, however, been some respite for regular office-goers, who were allowed to work from home. They had to adapt themselves to this online mode of working, but at least they received the required training and did not have to face stoppage of work and hence, salary. There was a government servant each in four of the families, and a teacher each in two, so these families enjoyed some security of employment. They did not even have to face pay cuts, and received their dues on time during lockdown. Those families seemed to be better off and much more relaxed than the others among the respondents.

The main areas where spending patterns were more or less forced to change were 'unnecessary expenditure', 'outdoor activities', 'reduced expenses', 'essentials', 'more online shopping' and 'bulk buying'. Respondents said that their spending during lockdown was significantly reduced, either due to necessity or due to the restrictions. They did not have to spend much on transport, and even if they wanted to spend on luxury items, going to the shops and shopping malls physically was not feasible. Less indulgence in extravagant food items became the norm, since restaurants remained closed too. Quite a few respondents pointed out that they had to curb all their unnecessary expenditure and buy only essentials. This trend is likely to continue even post COVID-19, since citizens will be more concerned about their disposable income. As brick-and-mortar stores were closed, or operated with very less capacity, people resorted to online shopping. Online grocery shopping has seen quite a splurge, but concerns remain about the way their items are delivered (contactless delivery). Among the essentials, there has been a new addition, as a stable and good Wi-Fi connection is mandatory, be it for online classes, examinations or working from home. The shortage of goods and limited store operations have ensured that as and when a product becomes available, people buy in bulk, and hoard it. Coming back to demand-supply theory, hoarding creates an artificial shortage, which increases the price to unprecedented levels, as had happened with hand sanitizers in the initial stages of the lockdown.

\section{(b) Impact on Students}

For almost all students, the switch to online learning has not been easy. Several problems crop up, which they have to overcome. The ones stated by respondents here can be summarized under the following categories - 'going virtual' and 'cognitive dissonance'.

(i) Going Virtual: Virtual here means the virtual mode of learning that students are now forced to get accustomed to. This means that there are no in-person class discussions with 
the faculty; there is a switch to e-books, with eyes glued to the computer or mobile screen and most importantly, missing out on the classroom atmosphere. Peer learning too takes a hit, especially in residential programmes such as MBA. In order to learn online, a lot of technological challenges are faced by the students, particularly the need for a stable internet connection. This has further necessitated increased spending on broadband connections. Often, students are missing classes or missing out on important discussions due to slow networks. Clearly, this is a major area of concern, be it for students or working professionals, amid a lockdown. Managing time, making a set time table and actually sticking to it, and juggling a virtual internship with online classes are among the toughest problems students are facing at home. Their attention span too is reduced, with so much of distraction in and around the house and also due to a lack of habit of attending classes online. The respondents are finding it difficult to keep themselves motivated, attend classes regularly and do their assignments. It is very clear that they would prefer actual classrooms to virtual learning any day, and are not yet ready to accept online classes. Thus, it bodes well with the literature on how the lack of facilities, coupled with huge loans, is proving detrimental to the students' performance (Onyema et al., 2020).

(ii) Cognitive Dissonance: The online mode of education has certainly affected the students, with nearly all respondents identifying one or more of the following issues, viz. 'financial problem', 'classroom experience', 'health', practical difficulty' and 'time management'. The financial problem stems from the fact that they had paid for a full-time classroom programme, but are now facing the possibility of a full year of online learning. They are not willing to pay the hefty amount charged, especially for the residential programme costs such as hostel and mess charges for an MBA degree. This is exactly where the cognitive dissonance lies, in the forced compliance behaviour of such students. Interactions with peers and having fruitful discussions inside the classroom are some of the experiences they are missing out on, and it is causing much frustration, boredom, anxiety and dissatisfaction among them. Such health issues, coupled with exam-related stress, are troubling them. Apart from this, there are several practical difficulties associated with this mode of teaching as well as taking examinations. According to some respondents who have taken online examinations already, most of them were very lengthy assignments, and it was more or less futile to study for any of them. Since this was not the conventional way of taking tests, they lost a lot of time in acclimatizing to the screen and mouse.

\section{(c) Impact on Employees/Businesses}

Nearly every respondent answered that his/her organization's business has been negatively affected by the pandemic. The major issues include 'core business' getting affected, 'loss of revenue/profits', 'labour shortage' and 'supply chain issues'. Teachers and educators have been hit pretty badly. While teaching anyone face to face has become quite impossible, they are uncertain of when schools will re-open, and have to adapt to the new ways and technology of teaching online. This has been a very challenging time for them.

(i) Supply Chain Issues \& Labour Shortage: Due to supply chain issues, many companies have found it difficult to complete the orders of clients in a timely manner. Furthermore, transport restrictions due to the lockdown have made the task seemingly impossible. Slowdown in business meant they were at times unable to pay the employees properly, and 
initiated pay cuts, hiring freeze as well as reducing the size of the workforce. This has led to panic and anxiety among employees who are already dealing with the challenges of working from home.

(ii) The Challenge of Technology: One of the major problems pointed out by the respondents was technical issues. While working with all this new technology, they found it very tedious and confusing, and wasted a lot of time getting accustomed to it. There were also time management problems, as being always at home made it difficult to maintain a work-life balance. Disruptions in internet connectivity led to a lot of problems, particularly communication. Even with smooth running internet, it has been difficult to communicate and collaborate with team members on any given project, according to a few. They remarked that it was more comfortable talking in a real conference room than a virtual one. There were also a few who complained that they had to work more hours than they would have done at office, since there were so many distractions and responsibilities to take care of at home, including managing their children, and, in some cases, pets.

(iii) Work from Home Support: When asked how this working from home situation can be improved, most respondents cited the internet and technical issues as the ones to resolve first. According to them, their respective organisations should provide them with, or at least compensate them for a good internet connection, laptops and also ergonomically suitable workspaces. This needs to be the prime focus of major corporates now, if work from home becomes the new normal. A technical support team that responds quickly should be kept ready at all times to entertain problems while using the new technology. The second most common requirement is to fix working hours rigidly, ensuring no further work-related disturbance post that. This is very important for the respondents to maintain their work-life balance, as they need to take care of their families too. Some have suggested that team bonding and employee engagement activities might be conducted at regular intervals, so that employees feel a little less stressed. They would also like some sessions and webinars on mental health to address the issues they might be facing while tackling this tough situation. This is a very serious issue, and research has found that this crisis can increase stress levels and have negative psychological effects, particularly in people with preexisting mental health conditions and also healthcare workers (Haider, Tiwana \& Tahir, 2020).

Creating a detailed business continuity plan, and sticking to it, is a good way to endure the crisis, according to nearly half of the respondents. One more crucial thing they all talked about was effective and regular communication. They are facing a huge amount of uncertainty and have a lot of unanswered questions, which are the main reasons for their anxiety. So, being very transparent about the whole situation, holding regular meetings to update employees about the company's performance, problems and policies, and frequently checking up on their and their family's health, will go a long way to alleviate the stress levels. Once organisations open their offices for business again, ensuring that all safety protocols are in place at all times will be the one major challenge, according to the respondents. 


\section{CONCLUSION AND RECOMMENDATIONS}

It is quite clear that the socio-economic implications of the virus are almost as severe as any other issue. People are living in fear, apprehension and mutual distrust. This should be eliminated at once, and the right way to do it would be more engaging and regular communication from the respective governments, principals and directors of institutes and employers (Brahmbhatt \& Dutta, 2008). In several countries, the head of state has made it a point to address the nation on a daily basis with updates and relief measures. This level of engagement is required so that citizens remain calm and respect the steps taken by the authorities. This can help smoothen things up a lot. The impact is more psychological, with many people panicking and not thinking straight. Hence, these unwarranted fears that come out of mere conjecture can be allayed easily by spreading more awareness. In India, multiple efforts have been made to spread extensive awareness about this virus. However, those were not enough, and more attractive and interactive means of communicating the facts and realities should be looked into.

The organizations should henceforth invest in a separate 'pandemic relief fund', while giving the same benefit to their employees as well. No one should suffer, and the hardships faced by labourers should never be repeated, so more intensive planning is required. The organisation needs to be more equipped to face all sorts of challenges in today's VUCA world, without having to compromise on its human resources. In this era of change, proper training and development of employees should include ability to work with the latest technology, and regular updating with these skills. One never knows which event would trigger a massive shift, and being flexible is the only way to keep going.

Students too have to be more conversant with the available technology, and be more accustomed to online classes and examinations. Even when classes resume, there should be certain examinations that institutes can conduct online, as part of a disaster preparedness plan in the future. Smart classrooms are already a thing in several institutes, and their popularity will expand now. Some sort of collaboration with online learning portals is a must, as the traditional pen and paper mode of education is fading into oblivion.

Overall, this pandemic has taught us several lessons - most of all, how to be prepared for any eventuality. Humans have always managed to survive and bounce back, and we shall do so this time as well. This research into all the socio-economic implications will hopefully be helpful in being innovative and being more prepared for any future pandemics.

\section{LIMITATIONS}

Although all efforts have been made to make the research as flawless as possible, certain limitations still remain. First, the geographical distribution of the respondents could not be expanded more, and has been restricted overwhelmingly to two cities. Having a more pan-India participants' pool might have helped us to draw some further interesting inferences. Second, the time of tentatively two months was short, and so the number of respondents had to be kept low. More interviews might have provided some more insights and could have improved the quality of the research. Finally, all interviews had to be taken via telephonic interviews on account of partial lockdown and mobility restrictions in place. Conducting a qualitative research during these challenging times was a huge challenge in itself. Face-to-face conversations are always better, as 
Lahiri \& Sinha $\mid$ A Study of the Socio-Economic Implications of the COVID-19 Pandemic

the expressions and emotions give away a lot more than what the person is saying, leading to more intriguing results.

\section{REFERENCES}

Abiad, A., Arao, M., Dagli, S., Ferrarini, B., Noy, L., Osewe, Platitas, R. (2020). The Economic Impact of the COVID-19 Outbreak on Developing Asia. ADB Briefs. DOI: http://dx.doi.org/10.22617/BRF200096

Bachman, D. (2020, March 03). The economic impact of COVID-19 (novel coronavirus). Deloitte Insights. https:/www2.deloitte.com/us/en/insights/economy/covid-19/economic-impactcovid-19.html

Barrett, C., Bisset, K. \& Leidig, J. (2010). Economic and social impact of influenza mitigation strategies by demographic class. The Journal on Infectious Disease Dynamics. doi: 10.1016/j.epidem.2010.11.002

Bloom, D. E. \& Canning, D. (n.d.). Epidemics and Economics. Harvard School of Public Health. RePEc:gdm:wpaper:0906

Brahmbhatt, M. \& Dutta, A. (2008). SARS Type Economic Effects during Infectious Disease Outbreaks. The World Bank East Asia and Pacific Region Chief Economist's Office. http://hdl.handle.net/10986/6440

Buheji, M., Mavric, B. \& Cunha, K. (2020). The Extent of COVID-19 Pandemic Socio-Economic Impact on Global Poverty - A Global Integrative Multidisciplinary Review. American Journal of Economics, 213-224. DOI: 10.5923/j.economics.20201004.02

Chen, C.-D., Chen, C.-C., Tang, W.-W. \& Huang, B.-Y. (2009). The Positive and Negative Impacts of the SARS Outbreak: A Case of the Taiwan Industries. The Journal of Developing Areas, 281-293. DOI:10.1353/jda.0.0041

Coibion, O., Gorodnichenko, Y. \& Weber, M. (2020). Labor markets during the Covid- 19 crisis: A preliminary view. Covid Economics, 40-58. http://www.nber.org/papers/w27017.pdf

Garrett, T. A. (2007). Economic Effects of the 1918 Influenza Pandemic: Implications for a Modern-day Pandemic. St. Louis: Federal Reserve Bank of St. Louis. https://files.stlouisfed.org/files/htdocs/publications/review/08/03/Garrett.pdf

Haider, I. I., Tiwana, F. \& Tahir, M. S. (2020). Impact of the COVID-19 Pandemic on Adult Mental Health. Pakistan Journal of Medical Sciences. DOI: 10.12669/pjms.36.COVID19S4.2756 
Jordà, Ò., Singh, S. R. \& Taylor, A. M. (2020). Longer-Run Economic Consequences of Pandemics. San Francisco: Federal Reserve Bank of San Francisco. DOI: https://doi.org/10.24148/wp2020-09

Keogh-Brown, M. R. (2014). Macroeconomic Effect of Infectious Disease Outbreaks. London: Elsevier Inc. DOI: doi: 10.1016/B978-0-12-375678-7.00608-8

Keogh-Brown, M. R. (2014). Macroeconomic Effect of Infectious Disease Outbreaks. London: Elsevier Inc. doi: 10.1016/B978-0-12-375678-7.00608-8

Keogh-Brown, M. R. \& Smith, R. (2008). The economic impact of SARS: How does the reality match the predictions? Health Policy 88, 110-120. doi: 10.1016/j.healthpol.2008.03.003

Kumar, S., Thombare, P. B. \& Kale, P. A. (2020, April 02). www.agrifoodmagazine.co.in. Retrieved from AGRICULTURE \& FOOD: e-Newsletter: http://www.agrifoodmagazine.co.in/2020/04/01/advanced-copy-volume-2-issue-4-april2020-complete-issue/

Leibovici, F. \& Santacreu, A. M. (2020). International trade of essential goods during a pandemic. Covid Economics, 59-99. DOI: https://doi.org/10.20955/wp.2020.010

Makridis, C. A. \& Wang, T. (2020). Learning from friends in a pandemic: Social networks and the macroeconomic response of consumption. Covid Economics, 100-133. DOI: https://dx.doi.org/10.2139/ssrn.3601500

Mamelund, S.-E., Shelley-Egan, C. \& Rogeberg, O. (n.d.). The association between socioeconomic status and pandemic influenza: protocol for a systematic review and metaanalysis. DOI: https://doi.org/10.1186/s13643-018-0931-2

McKibbin, W. \& Fernando, R. (2020). The Global Macroeconomic Impacts of COVID-19: Seven Scenarios. DOI: https://dx.doi.org/10.2139/ssrn.3547729

Oliver, N., Barber, X., Roomp, K. \& Roomp, K. (n.d.). The COVID19Impact Survey: Assessing the Pulse of the COVID-19 Pandemic in Spain via 24 Questions. DOI: $10.2196 / 21319$

Onyema, E., Nwafor, C., Faith, A., Sen, S., Atonye, F., Sharma, A. \& Alsayed, A. (2020). Impact of Coronavirus Pandemic on Education. Journal of Education and Practice. DOI: 10.7176/JEP/11-13-12

Overby, J., Rayburn, M., Hammond, K. \& Wyld, D. C. (2004). The China Syndrome: The Impact of the SARS Epidemic In Southeast Asia. Asia Pacific Journal of Marketing and Logistics. DOI: https://doi.org/10.1108/13555850410765131

Ozili, P. \& Arun, T. (2020). Spillover of COVID-19: Impact on the Global Economy. Social Science Research Network. DOI: 10.2139/ssrn.3562570 
Lahiri \& Sinha $\mid$ A Study of the Socio-Economic Implications of the COVID-19 Pandemic

Pagano, M., Wagner, C. \& Zechner, J. (2020). Disaster resilience and asset prices. Covid Economics, 1-39. http://www.csef.it/WP/wp563.pdf

Qui, Q., Rutherford, S., Mao, A. \& Chu, C. (2017). The Pandemic and its Impacts. Health, Culture And Society. DOI: https://doi.org/10.5195/hcs.2017.221

(2020). Shared Responsibility, Global Solidarity: Responding to the Socio-Economic Impacts of COVID-19. United Nations. https://unsdg.un.org/resources/shared-responsibility-globalsolidarity-responding-socio-economic-impacts-covid-19

Siu, A. \& Wong, R. Y. (2016, August 01). Economic Impact of SARS: The Case of Hong Kong. Asian Economic Papers. Retrieved from Asian Economic Papers. DOI: https://doi.org/10.1162/1535351041747996

Sun, L. \& Bunchapattanasakda, C. (2019, January). Employee Engagement: A Literature Review. International Journal of Human Resource Studies. DOI: 10.5296/ijhrs.v9i1.14167

World Health Organization (2020, July 4). Retrieved from WHO Coronavirus Disease (COVID19)

Dashboard: https://covid19.who.int/?gclid=EAIaIQobChMItfzmg9Ky6gIVVA4rCh2yAloEAAYASAAEgLN4PD_BwE

Zhong, B.-L., Luo, W., Li, H.-M., Zhang, Q.-Q., Liu, X.-G., Li, W.-T. \& Li, Y. (2020). Knowledge, attitudes, and practices towards COVID-19 among Chinese residents during the rapid rise period of the COVID-19 outbreak: a quick online cross-sectional survey. 1745-1752: International Journal of Biological Sciences. doi: 10.7150/ijbs.45221 